\title{
Construction project working site of environmental pollution and countermeasures
}

\author{
GENG ZHANG
}

\author{
Department of civil engineering, Xinjiang Construction Vocational Technology Institute ,Urumqi \\ 830026 ,China.
}

260021488@qq.com

\begin{abstract}
Keywords:construction project working site; environmental pollution; countermeasures Abstract: With the rapid development of China's economy, the urbanization process continues to accelerate, increasing the amount of large construction projects, at the same time because of the environmental pollution problems caused by the construction of more and more serious. In this paper, the construction of environmental species present first analysis to focus on the perspective of sustainable development, environmental pollution problems for the construction of proposed countermeasures to control environmental pollution.
\end{abstract}

\section{Introduction}

Since the reform and opening up, the role of the construction industry in China play an important economic development, with the rapid development of national economy, the construction industry has become a pillar industry of China's economic development. Although the construction industry has brought great opportunities for the development of the national community, but has produced a large number of pollutants in the course of construction, it has seriously affected the quality of life of the people, but also destroyed the balance of ecological environment. How to effectively solve the construction of environmental problems have gradually become the focus of attention.

\section{The construction of the main categories of environme ntal pollution}

\section{Noise Pollution}

Noise is the most common form of pollution impairs the living environment; construction noise may be generated by various types of construction machinery, construction process due to multiple devices simultaneously exacerbated the effects of noise; scaffolding and formwork handling, installation and noise removal, etc. can also be formed. General construction is carried out in stages, can be roughly divided into four stages, namely stage earthwork, piling stage, the construction stage structure and renovation phase. Used in various stages of construction equipment is not the same, noise pollution is not the same.

\section{water pollution}

Construction of the wastewater is mainly generated by the following water category: Cleaning well point dewatering, sludge generated by pile foundation construction, building materials and pipeline construction workers living water and wastewater. Temporary water leaking without corresponding facilities management follow-up, which will lead to the construction site sewage overflow; the mud liquid waste slurry discharged directly into the sewer, puree precipitated blocked drains, leading to secondary water pollution problems.

\section{air pollution}

Exhaust gas mainly from building decoration materials, where the pollutants are formaldehyde; paints, coatings, asphalt, adhesives in a variety of volatile organic compounds, such as aromatic hydrocarbons, straight chain hydrocarbons, halogenated hydrocarbons, aldehydes, ketones, alcohols and the like; building materials, air pollution caused by volatile organic compounds such as radiation and influence, often long-term continuous, some bedroom decoration a few year after, the 
formaldehyde concentration of BTEX was still seriously overweight. Pollutants produced building materials for the body's nervous system, blood system, respiratory system, reproductive system, etc. will produce great harm.

\section{dust pollution}

Dust is a major source of surface dust, but also to measure an important indicator of air quality of the urban environment. Construction dust pollution mainly refers to the construction site leveling operations, cement transport, concrete mixer, carpentry room sawdust, lime, stone and backfill yarn and other building materials in transportation, stacking and use, due to human or some meteorological factors. Dust great impact on human lungs, once inhaled into the lungs, it will irreversibly permanent retention, until death.

\section{waste pollution}

Building solid waste emissions from large, wide scope and far-reaching, difficult to degrade and persist in the soil will alter soil characteristics, not only the beauty of damage to the environment, the impact of appearance of the city, harm to human health, contamination of soil and ground water, reduce land economy value and so on. Waste pollution is mainly composed of soil, sediment, scattered mortar and concrete, masonry and concrete fragments tick chisel generated waste piling cut under reinforced concrete pile head, metal, bamboo wood, decoration produced a variety of building materials packaging and garbage and so on.

\section{Light Pollution}

Light pollution is a common building Following contaminated waste gas, waste water, waste and noise, and a new source of environmental pollution, light pollution at construction site mainly refers to the arc welding emitted light at night during the construction, etc. These Light pollution can sometimes affect people's normal sleep, some even once shine directly on the human eye, there is the danger caused by blind.

\section{Emissions of hazardous waste}

Construction site hazardous waste category is very large, such as chemical waste materials (often toxic) and its packaging, waste aluminum foil, industrial cotton, oil gloves, oil cotton cloth, paint brush, scrap thermometers (mercury); laboratory waste bottles (mainly potassium dichromate, sodium hydroxide, potassium hydroxide, acid, etc.); waste on-site cleaning tools, machinery maintenance liquid waste (some containing heavy metal ions); office waste copy paper, copier waste cartrid ges, ribbons of waste, waste batteries, waste disk, calculators waste, waste fluorescent tubes and so on.

\section{The construction site control measures pollution}

\section{strengthen supervision and management}

Construction enterprises should be based on ISO14000 environmental management standards, establish environmental management system, developed a series of environmental protection measures, prevention, comprehensive management, the establishment of the construction site of the environmental protection system, the responsibilities to each of the construction workers: First, the construction enterprises should enhance environmental awareness and improve environmental quality. Second, to establish ISO14000 environmental management system according to ring the requirements of the environmental management system standard, programming documents and construction and environmental protection work instructions, according to the standard requirements of construction organizations. Third, to strengthen the organization and management, construction project environmental protection unit set up a leading group headed by the project manager, the responsibility should gradually break down, the establishment of assessment system.

\section{Strengthening Prevention Technology}

In noise abatement, we should take effective measures to control the noise, because during the construction will be more frequently used construction equipment, noise sound source is stronger, and more noise sources superimposed noise level increases, so in different construction stages, regulatory requirements should be carried out on the construction site noise control. First of all, the 
construction site is completed before performing masonry walls, noise protection for sensitive target adjacent side noise reduction pre-installed security curtain around. Strengthen man-made noise control, eliminate human beat, loud noises. Secondly, according to the characteristics of the construction phase, a reasonable layout of the construction site, will produce high noise machinery and equipment disposed on the side away from the sound environmental protection goals. Then, try to choose low-noise muffler or with construction machinery equipment, adopt environmentally friendly working methods. Construction site construction vehicle access point should be kept away from sensitive sites, vehicle access to the site should be low, Jinming. Promoting the use of ready-mixed concrete. Strengthen the construction machinery inspection, repair and maintenance, to avoid mechanical failures run and generate abnormal noise pollution. Finally, strengthening the construction site noise monitoring, to achieve the purpose of the construction is not disturbing.

In terms of dust, but also to do science and technology-based, first, construction, living and work area equipped with hand watering hardening road sweeping to control dust. Second, prohibit mixing of concrete at the construction site, always use the ready-mixed concrete; dust material transport should be limited to the height, and the surface is sprayed with water and cover to prevent dust pollution. Third, the floor waste removal, is strictly prohibited to throw out garbage from floor surface. Fourth, the construction site used for decoration as much as possible the use of semi-finished raw materials (such as plaster), reduce dust. Fifth, centralized dust sifting, mixing and set enclosure, reducing pollution of the surround ing environment.

In waste water treatment: waste water settling ponds should be set in advance to import pro hibited directly discharged into the city sewer and river; sewage should be discharged into municipal sewage pipe network, together with the construction of waste water treated by the sewage treatment plant; for all types of vehicles, Fuel equipment used motor oil and lubricants should strengthen the management, all waste grease have to focus; paint, oil and other chemical materials polluting the classified storage, with sand, shovel, child care and other oil pan to prevent leakage caused by chemical contamination .

In terms of solid waste prevention: first, construction and garbage should be concentrated into a garbage tank, respectively, adequate coverage and timely removal; and second, the waste generated by carpentry work should be timely recovery of removal; and thirdly, electric welding scrap and waste Packaging materials should be collected, unified treatment; fourth, the scene of metal scrap should be collected into the pool. Effectively reduce light pollution: a reasonable preparation of construction work planned; try to choose lower-power lighting; lighting plus set shade, light direction concentrated in the construction area, the irradiation direction away from the residents; and take measures to block the welding work, welding arc avoid leakage.

\section{Conclusion}

In short, with the improvement of the quality of citizens civilization, environmental awareness is enhanced, citizens in the face of building construction pollution problems, the performance of more and more tough. Construction companies due to construction accidents disputes and increasing pay compensation to the enterprise also caused some damage. "Sustainable development and environmental protection" is the theme of our times, construction companies only fully aware of this point, to take the necessary measures to actively eliminate and reduce pollution during construction, will inevitably win-win results.

\section{References}

[1] GuoZhi Xin Talking about the construction of Environmental Pollution and Control Measures [j] Science and Technology Innovation Herald .2012 (01): 208-210 
[2] YuPing Li Construction environmental analysis and Green Construction Management Method [j] Science and Technology Innovation Herald 2010 (35): 315-317. Measures

[3]Chao Yuan Luo Measures to eliminate the construction of environmental pollution and safety issues [j] Towns Construction 2009 (04): 211-213

[4] Yue Lin Niu, FengPing Luo etc. On the construction site of the Environmental Pollution and Control Measures [j] Resources Environment \& Engineering .2006,20 (03): 114-116 